\title{
Prevalence of Ischemia, Health-Related Quality of Life, Medical use and Expenses by Physical Activity and Ischemia Status in Korean Adults
}

\author{
Byung-Kun Lee PhD \\ Division of Convergence of Sport, SangMyung University, Cheonan, Korea
}

PURPOSE: The purpose of this study is to analyze the different prevalence of ischemia of Korea adults, and to compare the HealthRelated Quality of Life (HRQoL), annual personal medical use and expenses according to physical activity and ischemia status.

METHODS: The 2018 Korea Medical Panel data was used (13,791 adults and 604 ischemia). Physical activity was measured with IPAQ and converted to MET-minutes per week. The physical activity group was classified as less than 600 MET-min per week in the inactive group, 600-3,000 MET-min per week in the minimally active group, and 3,000 MET-min more per week in the active group.

RESULTS: The prevalence of ischemia was low in the inactive group compared to the minimally active group and the active group $(\mathrm{OR}=0.75, p<.01)$ and the active group $(\mathrm{OR}=0.36, p<.001)$. In both ischemic and non-ischemic groups, HRQL was the lowest in the inactive group $(p<.05)$. Inpatient days and emergency days showed no significant difference in according to the physical activity level and the ischemia status. However, within the group with ischemia, the outpatient days of inactive group were $42.8 \%$ higher $(p<.05)$ and minimally active group was $4.3 \%$ higher $(p>.05)$ compared to the active group $(32.5 \pm 32.1$ days $)$ respectively. Within the group with ischemia, the medical expenses of inactive group were $5.2 \%$ lower $(p>.05)$ and minimally active group was $33.9 \%$ lower $(p<.05)$ compared to the active group $(\$ 1,738 \pm 2,457)$ respectively.

CONCLUSIONS: Higher physical activity results in a lower prevalence of ischemia, and higher physical activity results in positive HRQoL and outpatient days in ischemia group. However Annual personal medical expenses showed a significant difference according to the level of physical activity in ischemia group

Key words: Prevalence of ischemia, Health-Related Quality of Life, Medical use, Physical activity, Korean Medical Panel

\section{INTRODUCTION}

Lack of physical activity causes various problems in terms of health management. According to the World Health Organization (WHO) [1], lack of physical activity is one of the top 10 causes of death worldwide and a major risk factor for non-infectious diseases such as cardiovascular disease, diabetes and cancer. The Korean Medical Panel was intensively investigating ischemic heart disease, hypertension, diabetes, hyperlipidemia, tuberculosis, cerebrovascular disease, and arthropathy as seven chronic diseases. The seven leading causes of death in the United States in 2019 were heart disease, cancer, unintentional injuries, chronic lower respiratory tract disease, stroke, Alzheimer's disease and diabetes [2].

Among them, ischemic heart disease was a disease in which adequate blood supply to the heart is not achieved due to a blood flow disorder in the coronary arteries that supply blood to the heart. Since ischemia was mostly caused by atherosclerosis of the coronary arteries, it is also called coronary artery disease. The narrowing of the coronary arteries was caused by atherosclerosis in which cholesterol was deposited in the blood vessels and the accompanying thrombus. Elevated blood lipid levels, including cholesterol and triglycerides, from a variety of underlying causes

\footnotetext{
Corresponding author: Byung-Kun Lee Tel +82-10-4251-7999 Fax +82-41-550-5339 E-mail bkleedsmu.ac.kr

*This work was supported by Research fund of SangMyung University 2020.

Received 28 Sep 2021 Revised 21 Nov 2021 Accepted 29 Nov 2021
}

@) This is an Open Access article distributed under the terms of the Creative Commons Attribution Non-Commercial License (https://creativecommons.org/licenses/by-nc/4.0/) which permits unrestricted non-commercial use distribution, and reproduction in any medium, provided the original work is properly cited. 
can lead to atherosclerosis and pancreatitis [3]. The number of average hospitalization days for patients with ischemia in Korea was 9.7 days, which ranks third among the Organization for Economic Cooperation and Development countries (OECD) [4]. Ischemia has been known to be the leading cause of hospitalization and death for many years [5], and over the past 20 years, the associated mortality rate has been declining, which is due to the transformation of ischemic heart disease into a chronic disease [6].

Weight control with regular physical activity and an appropriate diet reduces metabolic syndrome risk factors such as cholesterol and triglycerides. Maintaining an appropriate level of physical activity was a key factor in controlling atherosclerosis risk factors and reducing the incidence of cardiovascular events through weight loss and lowering blood pressure [7]. Physical activity has been reported to be associated with reduced risk factors for cardiovascular disease and reduced coronary artery disease, stroke and heart failure [8-12]. Yifei et al. reported that as the amount and intensity of physical activity increased, peripheral vascular disease and limb ischemia decreased, and that physical activity was important for maintaining vascular health [13]. Achieving and maintaining adequate physical activity was covered by most key management guidelines [14].

It is reported that the group that improved the lifestyle, such as regular physical activity, reduced the cost of disease management as well as weight loss, blood sugar and blood pressure control, and improved quality of life and comorbidities $[15,16]$. Health-related quality of life (HRQoL) was a multidimensional concept based on subjective attitudes and experiences toward physical, mental, and social health [17]. HRQoL was affected by health-related behaviors such as smoking, drinking, sleeping, and physical activity, and physical activity is an important influencing factor [18]. In the case of elderly subjects, this variable was greatly affected by chronic diseases and functional decline according to aging [19]. Therefore, it is meaningful to analyze the effect of physical activity on patients' HRQoL with chronic diseases such as ischemia.

As a result of comparing the risk of exercise and metabolic syndrome, the risk rate of the group exercising for 3 hours or more per week was $48 \%$ lower than that for 1 hour or less per week, and the high-intensity exercise group for 60 minutes or more had a lower risk by $2 / 3$ [20]. In terms of physical strength and prevalence, the prevalence of hypertension in the 3rd quartile group was 0.93 and 0.77 in the 4th quartile group than in the lowest grip strength group, and as muscle strength increased, the prevalence of hypertension decreased [21]. Lee also said that the higher the grip strength, the greater the participation in high-intensity exercise and flexibility exercise, and the lower the prevalence of hypertension [21].

A number of studies have also been reported that analyze the relationship between physical activity, disease, and medical use and medical expenses. It has been reported that inactive people were 38\% more likely to use inpatient care than actively physically active people [22]. In a study comparing the degree of physical activity and medical use, as a result of comparing the inactive group and the active group, the use of hospitalization of the inactive group was 0.54 times less, and the use of pharmacy was 0.75 times less, and the frequency of medical use was also low [23]. Woolcott reported that the inactive group had a $\$ 1,214.15$ higher medical expenses than the active group, and that there was a significant correlation between the level of physical activity and the length and frequency of hospitalization [24]. Wu et al. [25] reported that as a result of diabetic patients participating in physical activity for 30 minutes and more 5 times per week, the total medical expenses of the exercise group was $61.8 \%$ of that of the non-exercise group $(p<.001)$, and the hospital stay was $28 \%$ shorter. Accurately predicting and managing the number of days spent in the hospital will reduce the patient's medical expenses and enable efficient management of hospital resources [26]. Analyzing the factors affecting the length of stay in patients with ischemic heart disease is an important study in terms of length of stay management and medical expenses management.

There were some reports that the risk factors related to ischemic heart disease are improved depending on the level of physical activity or physical fitness, but there were very few studies on the prevalence of ischemia according to the level of physical activity using national design survey data. It is also necessary to comprehensively analyze the health-related quality of life, medical use, and medical expenses of patients with ischemia according to the physical activity group.

The purpose of this study is to analyze the difference in the prevalence of ischemia according to physical activity among Korean adults, and to compare HRQoL, annual personal medical use and expenses according to physical activity and ischemia status.

\section{METHODS}

\section{Analysis data and subjects}

The data of this study was the most recently published 2018 annual data among the Korean medical panels jointly hosted by the Korea Insti- 
tute for Health and Social Affairs and the National Health Insurance Corporation. The Korea Medical Panel Survey was a government-designated statistical survey with approval number 92012 (2007). This was data from a nationwide panel survey project that investigates data on health and medical use status, health level and health behavior, and medical expenditure level.

The Korea Medical Panel was based on the 2005 Population and Housing Census. Since 2008, it has been investigating general household members, health behavior and level, disease management, economic activity, health and medical use status and medical use. For the selection of the survey target, using the two-step probability proportional stratified cluster sampling method, the sample survey area (about 350) colony extraction and sample household extraction were performed. In 2008, 7,866 households were included, but missing households occurred, and a new 2,222 households were added in 2013. The analysis data of this study was conducted from March to September 2018, and a total of 13,791 adult males and females over the age of 20 were extracted. Among them, 604 patients diagnosed with ischemia by doctors were analyzed. Ischemia was diagnosed using methods such as echocardiography, nu- clear stress test, coronary angiography, and cardiac CT scan. Various data were integrated and analyzed based on the unique household and member ID. Table 1 shows the population status, physical data, and health and disease behavior data of all study subjects and ischemia patients.

\section{Variable Definition and Measurement}

Physical activity was investigated using the short form of the International Physical Activity Questionnaire (IPAQ). The IPAQ long form consists of 27 questions, allowing in-depth research, and the short form consists of 7 questions and was suitable for national or regional management systems [27]. The IPAQ short form surveys the number of days per week and average daily activity time of walking, moderate activity and vigorous physical activity for more than 10 minutes in the past week. The exercise intensity was 3.3 MET for walking, 4.0 MET for moderate activity, and 8.0 MET for vigorous activity. The amount of physical activity was calculated by multiplying the intensity of walking, moderate activity, and vigorous activity among the questionnaire data by the number of days of participation per week and the average activity time

Table 1. Characteristics of total population $(\mathrm{N}=13,791)$ and ischemia patients $(\mathrm{N}=604)$

\begin{tabular}{|c|c|c|c|c|c|c|c|}
\hline \multirow{2}{*}{ Variables } & \multirow{2}{*}{ Categories } & \multicolumn{3}{|c|}{ Total population $(\mathrm{N}=13,791)$} & \multicolumn{3}{|c|}{ Ischemia patients $(\mathrm{N}=604)$} \\
\hline & & $\mathrm{N}$ & $\%$ & Mean \pm SD & $\mathrm{N}$ & $\%$ & Mean \pm SD \\
\hline \multicolumn{8}{|l|}{ Demographics } \\
\hline \multirow[t]{2}{*}{ Gender } & Male & 6,483 & 47 & & 307 & 50.8 & \\
\hline & Female & 7,308 & 53 & & 297 & 49.2 & \\
\hline Age & & & & $53.6 \pm 18.1$ & & & $72.9 \pm 10.0$ \\
\hline \multicolumn{8}{|c|}{ Physical measurements } \\
\hline Height $(\mathrm{cm})$ & & & & $163.5 \pm 9.2$ & & & $160.3 \pm 9.0$ \\
\hline Weight (kg) & & & & $62.9 \pm 11.7$ & & & $62.0 \pm 11.27$ \\
\hline Body mass index & & & & $23.4 \pm 3.2$ & & & $24.0 \pm 3.2$ \\
\hline \multicolumn{8}{|c|}{ Health habit and disease } \\
\hline \multirow[t]{2}{*}{ Smoking } & Smoker & 4,787 & 34.7 & & 289 & 47.8 & \\
\hline & Nonsmoker & 8,246 & 59.8 & & 299 & 49.5 & \\
\hline \multirow[t]{4}{*}{ Drinking } & Nondrinker & 3,481 & 26.7 & & 245 & 41.7 & \\
\hline & Below 1 time per month & 3,031 & 23.3 & & 179 & 30.4 & \\
\hline & 1 to 3 times per month & 2,834 & 21.7 & & 74 & 12.6 & \\
\hline & Above 1 time per week & 3,686 & 28.3 & & 90 & 15.3 & \\
\hline \multirow[t]{2}{*}{ Disease } & Ischemia & 604 & 4.4 & & 604 & 100.0 & - \\
\hline & Non-Ischemia & 13,183 & 95.6 & & 0 & 0.0 & - \\
\hline \multicolumn{8}{|l|}{ Medical use } \\
\hline \multirow[t]{2}{*}{ Inpatient } & Inpatients & 1,329 & 9.6 & & 126 & 20.9 & \\
\hline & Non-inpatients & 12,462 & 90.4 & & 478 & 79.1 & \\
\hline \multirow[t]{2}{*}{ Outpatients } & Outpatients & 12,007 & 87.1 & & 595 & 98.5 & \\
\hline & Non-outpatients & 1,784 & 12.9 & & 9 & 1.5 & \\
\hline \multirow[t]{2}{*}{ Emergency } & Emergency patients & 983 & 7.1 & & 99 & 16.4 & \\
\hline & Non-emergency patients & 12,808 & 92.9 & & 505 & 83.6 & \\
\hline
\end{tabular}


per day, converting it to MET (metabolic equivalent)-minutes per week, and adding up all three activity amounts. The physical activity group was classified as less than 600 MET-min per week in the inactive group, 600-3,000 MET-min per week in the minimally active group, and 3,000 MET-min or more per week in the active group [27].

Health-related quality of life was measured using the Korean version of Euro-QoL-5D (EQ-5D) developed by the EuroQoL group. EQ-5D was Mobility (M), Self-Care (SC), Usual Activities (UA), Pain/discomfort (PD), Anxiety/Depression (AD) consists of 5 items. Each item was divided into three levels: 'No problem at all', 'Somewhat problematic', and 'There is a lot of problem'. The specific estimation method of health-related quality of life was as Equation (1) [28].

$\mathrm{Y}=1-(0.050+0.096 \times \mathrm{M} 2+0.418 \times \mathrm{M} 3+0.046 \times \mathrm{SC} 2+0.136 \times \mathrm{SC} 3+0.051 \times$

$\mathrm{UA} 2+0.208 \times \mathrm{UA} 3+0.037 \times \mathrm{PD} 2+0.151 \times \mathrm{PD} 3+0.043 \times \mathrm{AD} 2+0.158 \times$

$\mathrm{AD} 3+0.050 \times \mathrm{N} 3)$

A case of ' 1 ' for all five items was regarded as a state of complete health, and the EQ-5D value of a healthy person at this time was set as ' 1 '. Based on this, if there is a level 2 or level 3 response, the EQ-5D value is calculated using the weight formula according to Equation 1 above. M2 was when the response to exercise capacity was '2', M3 was when the response to exercise capacity was ' 3 ', and the rest of the terms were defined in the same way. N3 was deducted if one responds to level 3, which was the worst unhealthy state. In terms of medical use, the number of hospitalization days, outpatient days, and emergency room use days per year were investigated. Personal medical expenses were the sum of prescription drug prices related to inpatient, outpatient and emergency medical expenses received by one household member for one year.

\section{Statistical analysis}

Frequency analysis was performed on gender, health habits and diseases, and descriptive analysis was performed on age and physical characteristics. Logistic regression was performed to examine the difference of the physical activity level on the prevalence of ischemia, and covariates were gender, age, smoking, drinking, height, weight and BMI. Smoking was divided into smoking or not, and drinking was classified as abstinence from alcohol throughout life, sobriety for the past year, less than once a month, once a month, 2-3 times a month, once a week, 2-3 times a week, almost every day, and separately analyzed. Analysis of covariance (ANCOVA) was performed to examine the difference of HRQoL, medical use and expenses as dependent variables, and the post-hoc was performed using Bonferroni's method. The t-test was performed to compare the difference according to ischemia. The statistical significance level was .05 .

\section{RESULTS}

\section{Difference of Ischemia prevalence}

Table 2 shows the results of logistic regression analysis to determine the difference in the prevalence of ischemia according to the physical activity level. As a result of analysing the prevalence of ischemia in the inactive group as 1.00, the OR (Odds Ratio) of the prevalence in the minimally active group was $0.75(95 \% \mathrm{CI}=0.63-0.89)$, which was significantly lower by $25.0 \%(p<.001)$, the OR of the prevalence of the active group was $0.36(95 \% \mathrm{CI}=0.22-0.57)$, which was lower by $64.0 \%(p<.000)$. As a result of analysing the prevalence of ischemia with covariates, and with an inactive group prevalence of 1.0, the OR of the minimally active group was 1.05 (95\% CI=0.87-1.23), similar to $1.0 \%$. There was no significant difference $(p=0.59)$, but the OR of the prevalence of the active group was $0.61(95 \% \mathrm{CI}=0.38-1.00)$, which was $39.0 \%(p<.05)$ lower. That is, as the level of physical activity increased, the prevalence of ischemia decreased from $25.0 \%$ to $64.0 \%$, and there was a significant difference in both the minimally active and active groups. When covariates were controlled, the minimally active group increased by $5.0 \%(p=.59)$, and the active group decreased by $39.0 \%$, showing a significant difference $(p<.05)$.

Table 2. Difference of ischemia prevalence according to the physical activity level

\begin{tabular}{|c|c|c|c|c|c|}
\hline Physical activity group & $\mathrm{N}(\%)$ & Unadjusted OR ( $95 \% \mathrm{Cl})$ & $p$ & Adjusted OR (95\% Cl) & $p$ \\
\hline 1st grade inactive & $6,206(49.9)$ & 1.00 & & 1 & \\
\hline 2nd grade minimally active & $5,283(42.5)$ & $0.75(0.63-0.89)$ & $.001^{* *}$ & $1.05(0.87-1.23)$ & .59 \\
\hline 3rd grade active & $955(7.7)$ & $0.36(0.22-0.57)$ & $.000^{* * * *}$ & $0.61(0.38-1.00)$ & $.04^{*}$ \\
\hline
\end{tabular}

OR, Odds ratio; $95 \% \mathrm{Cl}, 95 \%$ Confidence Interval.

Adjusted factors: gender, age, smoking, frequency of drinking, height, weight, BMl.

${ }^{*} p<.05,{ }^{* *} p<.01,{ }^{* * *} p<.001$ significance level of Logistic regression. 


\section{Difference of HRQoL}

Table 3 shows the difference in HRQoL and usual activities according to the physical activity level and the ischemia status. HRQoL and usual activities showed a significant interaction effect between the activity level and the ischemia status $(p<.01)$. In HRQoL and usual activities, there were significant differences according to the physical activity level in both the ischemia and non-ischemia $(p<.001)$. In both ischemia and non-ischemia, HRQoL was the lowest in the inactive group $(p<.05)$, indicating negative results, and those of non-ischemia were higher than ischemia in all three active groups $(p<.05)$. In both ischemia and nonischemia, usual activities were the highest in the inactive group $(p<.05)$, indicating negative results, and those of ischemia were higher than nonischemia in inactive and minimally active groups $(p<.05)$. The results of Mobility (M), Self-Care (SC), Pain/discomfort (PD), Anxiety/Depression
(AD) were similar to that of usual activities. Therefore, these results were not shown.

\section{Difference of medical use and expenses}

Table 4 shows the difference of medical use and expenses according to the physical activity level and the ischemia status. Both the inpatient days and outpatient days showed a significant interaction effect between activity level and ischemia status $(p<.01)$. There was no significant difference in the inpatient days according to the physical activity level $(p>.05)$ and the ischemia status $(p>.05)$. The outpatient days showed a significant difference between the 3 groups of active level $(p<.01)$. Within the group with ischemia, the outpatient days of inactive group were $42.8 \%$ higher $(p<.05)$ and minimally active group was $4.3 \%$ higher ( $p>.05)$ compared to the active group ( $32.5 \pm 32.1$ days) respectively. The

Table 3. Difference of HRQoL and usual activities according to the physical activity level and the ischemia status

\begin{tabular}{|c|c|c|c|c|c|c|}
\hline \multirow{2}{*}{ Contents } & \multicolumn{3}{|c|}{ HRQoL } & \multicolumn{3}{|c|}{ Usual activities } \\
\hline & Ischemia & Non-ischemia & $p$ of t-test & Ischemia & Non-ischemia & $p$ of t-test \\
\hline Inactive group & $\begin{array}{c}0.637 \pm .358^{\mathrm{a}} \\
(\mathrm{N}=348)\end{array}$ & $\begin{array}{c}0.822 \pm 0.242^{\mathrm{a}} \\
(\mathrm{N}=6,206)\end{array}$ & $.000^{* * *}$ & $1.38 \pm 0.55^{\mathrm{a}}$ & $1.14 \pm 0.37^{\mathrm{a}}$ & $.000^{* * *}$ \\
\hline Minimally active group & $\begin{array}{c}0.833 \pm .190^{b} \\
(\mathrm{~N}=221)\end{array}$ & $\begin{array}{c}0.882 \pm 0.151^{\mathrm{b}} \\
(\mathrm{N}=5,283)\end{array}$ & $.000^{* * *}$ & $1.09 \pm 0.29^{b}$ & $1.05 \pm 0.21^{\mathrm{b}}$ & $.024^{*}$ \\
\hline Active group & $\begin{array}{c}0.818 \pm 0.14^{\mathrm{a}, \mathrm{b}} \\
(\mathrm{N}=19)\end{array}$ & $\begin{array}{c}0.881 \pm 0.151^{b} \\
(\mathrm{~N}=955)\end{array}$ & .071 & $1.05 \pm 0.23^{\mathrm{a}, \mathrm{b}}$ & $1.04 \pm 0.19^{\mathrm{a}, \mathrm{b}}$ & .800 \\
\hline$p$ of ANCOVA & $0.000^{* * *}$ & $0.000^{* * * *}$ & & $0.000^{* * * *}$ & $0.000^{* * *}$ & \\
\hline$p$ of 2 way ANCOVA & $\begin{array}{r}\text { Ac } \\
\text { Isch } \\
\text { Inte }\end{array}$ & $\begin{array}{l}244 \\
0.280 \\
00^{* * *}\end{array}$ & & $\begin{array}{l}\text { Active } \\
\text { Ischemi } \\
\text { Interact }\end{array}$ & $\begin{array}{l}.207 \\
0.494 \\
00^{* * * *}\end{array}$ & \\
\hline
\end{tabular}

HRQoL, Health-Related Quality of Life.

Significance level of ANCOVA (adjusted factors: gender, age, smoking, frequency of drinking, height, weight, BMI) and independent t-test.

${ }^{a, b}$ Each character means significant different $(p<.05) .{ }^{*} p<.05,{ }^{* *} p<.01,{ }^{* * *} p<.001$.

Table 4. Difference of medical use and expenses according to the physical activity level and the ischemia status

\begin{tabular}{|c|c|c|c|c|c|c|}
\hline \multirow{2}{*}{ Contents } & \multicolumn{3}{|c|}{ Annual inpatients days } & \multicolumn{3}{|c|}{ Annual outpatient days } \\
\hline & Ischemia & Non-ischemia & $p$ of t-test & Ischemia & Non-ischemia & $p$ of t-test \\
\hline \multirow[t]{3}{*}{ Inactive group } & $1.79 \pm 1.49$ & $1.46 \pm 1.08$ & .058 & $46.4 \pm 46.6$ & $23.8 \pm 29.0$ & $.000^{* * *}$ \\
\hline & $(119.30 \%)$ & (108.90\%) & & $(142.8 \%)^{b}$ & (128.20\%) & \\
\hline & $(\mathrm{N}=81)$ & $(\mathrm{N}=664)$ & & $(\mathrm{N}=345)$ & $(\mathrm{N}=5,490)$ & \\
\hline \multirow{3}{*}{ Minimally active group } & $1.28 \pm 0.62$ & $1.48 \pm 1.21$ & .328 & $33.9 \pm 28.2$ & $20.3 \pm 23.2$ & $.000^{* * *}$ \\
\hline & (85.30\%) & (104.40\%) & & $(104.3 \%)^{a}$ & (109.30\%) & \\
\hline & $(\mathrm{N}=36)$ & $(\mathrm{N}=431)$ & & $(\mathrm{N}=221)$ & $(\mathrm{N}=4,693)$ & \\
\hline \multirow[t]{3}{*}{ Active group } & $1.5 \pm 1.0$ & $1.34 \pm 1.04$ & .769 & $32.5 \pm 32.1$ & $18.56 \pm 21.04$ & .075 \\
\hline & (100.00\%) & $(100.00 \%)$ & & $(100.0 \%)^{a, b}$ & $(100.00 \%)$ & \\
\hline & $(\mathrm{N}=4)$ & $(N=73)$ & & $(\mathrm{N}=19)$ & $(\mathrm{N}=843)$ & \\
\hline$p$ of ANCOVA & .169 & .678 & & $.005^{* *}$ & .079 & \\
\hline \multirow[t]{3}{*}{$p$ of 2 way ANCOVA } & \multicolumn{2}{|c|}{ Active level: 0.520} & \multicolumn{4}{|c|}{ Active level: 0.319} \\
\hline & \multicolumn{2}{|c|}{ Ischemia status: 0.945} & & \multicolumn{2}{|c|}{ Ischemia status: $0.026^{*}$} & \\
\hline & \multicolumn{2}{|c|}{ Interaction: $0.049^{*}$} & & \multicolumn{2}{|c|}{ Interaction: $0.003^{* *}$} & \\
\hline
\end{tabular}


Table 4. Continued

\begin{tabular}{|c|c|c|c|c|c|c|}
\hline \multirow{2}{*}{ Contents } & \multicolumn{3}{|c|}{ Annual emergency days } & \multicolumn{3}{|c|}{ Annual personal medical expenses+ } \\
\hline & Ischemia & Non-ischemia & $p$ of t-test & Ischemia & Non-ischemia & $p$ of t-test \\
\hline \multirow[t]{3}{*}{ Inactive group } & $1.57 \pm 1.68$ & $1.32 \pm 0.77$ & .230 & $\$ 1,692 \pm 2,277$ & $\$ 757 \pm 1,408$ & $.000^{* * *}$ \\
\hline & $(157.00 \%)$ & (110.90\%) & & $(94.8 \%)^{b}$ & $-126.10 \%$ & \\
\hline & $(\mathrm{N}=70)$ & $(\mathrm{N}=463)$ & & $(\mathrm{N}=348)$ & $(\mathrm{N}=6206)$ & \\
\hline \multirow[t]{3}{*}{ Minimally active group } & $1.21 \pm 0.51$ & $1.21 \pm 0.53$ & .961 & $\$ 1,149 \pm 1,188$ & $\$ 665 \pm 1,312$ & $.000^{* * *}$ \\
\hline & $(121.00 \%)$ & $(101.60 \%)$ & & $(66.1 \%)^{a}$ & $-110.80 \%$ & \\
\hline & $(\mathrm{N}=24)$ & $(\mathrm{N}=332)$ & & $(\mathrm{N}=221)$ & $(\mathrm{N}=4693)$ & \\
\hline \multirow[t]{3}{*}{ Active group } & $1.00 \pm 0.00$ & $1.19 \pm 0.52$ & .478 & $\$ 1,738 \pm 2,457$ & $\$ 600 \pm 1,008$ & $.000^{* * * *}$ \\
\hline & $(100.00 \%)$ & $(100.00 \%)$ & & $(100.0 \%)^{a, b}$ & $-100.00 \%$ & \\
\hline & $(\mathrm{N}=4)$ & $(\mathrm{N}=62)$ & & $(\mathrm{N}=19)$ & $(\mathrm{N}=995)$ & \\
\hline$p$ of ANCOVA & .502 & .336 & & $.004^{* *}$ & .318 & \\
\hline \multirow[t]{3}{*}{$p$ of 2 way ANCOVA } & \multicolumn{2}{|c|}{ Active level: 0.288} & \multicolumn{4}{|c|}{ Active level: 0.412} \\
\hline & \multicolumn{2}{|c|}{ Ischemia status: 0.930} & & \multicolumn{2}{|c|}{ Ischemia status: $0.020^{*}$} & \\
\hline & \multicolumn{2}{|c|}{ Interaction: 0.260} & & \multicolumn{2}{|c|}{ Interaction: $0.002^{* *}$} & \\
\hline
\end{tabular}

Annual personal medical expenses = inpatient medical expenses + inpatient drug expenses + outpatient drug expenses + outpatient medical expenses + emergency medical expenses + emergency prescription drug expenses $(1 \$=W 1,100)$.

significance level of ANCOVA (adjusted factors: gender, smoking, frequency of drinking, height, weight, BMI) and independent t-test.

${ }^{\mathrm{a}, \mathrm{b}}$ Each character means significant different $(p<.05)$.

${ }^{*} p<.05,{ }^{* *} p<.01,{ }^{* * *} p<.001$.

outpatient days showed a significant difference in according to the ischemia status $(p<.05)$, and that of ischemia were 66.9-94.9\% higher than that of non-ischemia according to the active level. The emergency days was no significant difference in according to the physical activity level ( $p>.05)$ and the ischemia status ( $p>.05)$, and there was no significant interaction $(p>.05)$. Annual medical expenses showed a significant difference according to ischemia status $(p<.05)$, and a significant interaction between physical activity and ischemia status was found $(p<.001)$. Within the group with ischemia, the medical expenses of inactive group were $5.2 \%$ lower $(p>.05)$ and minimally active group was $33.9 \%$ lower $(p<.05)$ compared to the active group $(\$ 1,738 \pm 2,457)$ respectively, and showing a significant difference among the 3 groups $(p<.01)$. However, in case of non-ischemia group the medical expenses were a no significant difference among the activity 3 groups ( $p>.05$ ). Within the ischemia group, annual personal medical expenses showed the lowest in the minimally active group, and the inactive and active groups were similar. However, within in the non-ischemic group, there was no significant difference in personal medical expenses among activity levels $(p>.05)$.

\section{DISCUSSION}

National health-related data include the Korean Medical Panel, which repeatedly surveys the same subjects, and the National Health and $\mathrm{Nu}$ trition Examination Survey, which is a cross-sectional data. In this study, the most recently surveyed data from the Korean Medical Panel in 2018 was used.

Continued participation in regular physical activity was associated with coronary heart disease [29], hypertension [30], diabetes [31,32] were reported to reduce the overall risk of death as well as risk factors for chronic diseases [33]. It has been reported that regular aerobic exercise such as jogging and cycling lowers blood pressure at rest by $3.5 / 2.5$ $\mathrm{mmHg}$ [34]. Moraes reported that regular exercise had a positive effect on improving circulatory and cardiovascular disease [35]. Helmrich et al. reported that for every $500 \mathrm{kcal}$ increase in physical activity, the diabetes prevention effect increased by 6\% [36]. In the case of ischemic heart disease in this study, the ORs of the minimally active and active groups were $0.75(p<.01)$ and $0.36(p<.001)$ compared to the inactive group, which supported that the prevalence of ischemia increased with decreased physical activity (Table 2). The decrease in the prevalence of ischemia was slightly higher than that of hypertension, hyperlipidemia, and diabetes. Lifestyle improvement has been shown to improve blood sugar and diabetes disease, lower blood pressure, reduce weight, and improve quality of life, as well as disease management and reduction in medical expenses $[15,16,37]$.

Quality of life was a factor that directly affects the health of the elderly, and it was known that physical activity was very effective as a method for improving the quality of life of the elderly [38]. It has been reported that regular physical activity improves daily performance ability and has 
a positive effect on independent life, thereby improving quality of life [39]. In this study, the HRQoL of the minimally and active groups were positively higher than those of the inactive group (Table 3). This means that minimal activity alone improved the quality of life. Fraga et al. [40] supported the results of this study by reporting that walking exercise was effective in improving the quality of life of elderly women.

A number of studies have also been reported that analyzed the relationship between the level of physical activity and medical use. Wollcott reported that physical activity had a significant negative correlation with hospitalization frequency and length of stay [24]. Wu et al. [25] reported that among diabetic patients, the medical expenses of the exercise group, which participated more than 5 times per week, were $61.8 \%$ of that of the non-exercise group $(p<.001)$, and that the hospitalization period was $28 \%$ shorter than that of the non-exercise group $(p<.01)$. Active physical activity reduces the number of days of hospital outpatient visits, and regular exercise at least once a week reduces health problems requiring medical use compared to non-exercise [23]. Sari also reported that the inactive group had 38\% more hospitalizations, 13\% more special services, and 5.5\% more doctor visits than the active group [22]. In a study on the relationship between physical activity and medical use, the moderately physically active group showed 12\% less outpatient use and 30\% less inpatient use than the inactive group [41]. In this study, there was no significant difference in annual days of inpatient according to the degree of physical activity in the case of ischemia (Table 4). Ischemia was influenced by several factors, such as patient characteristics and hospital characteristics, and the treatment process is complicated, so the length of stay differs, influenced by heart rate, systolic and diastolic pressure, age, and insurance status at hospitalization [26]. It has been reported that the causes of increase in days of inpatient for patients with ischemia include CABG (coronary artery bypass surgery), emergency hospitalization, acute myocardial infarction, and medical benefits [42]. In terms of comorbid diseases, the length of stay was very high in patients with diabetes [43], and in terms of surgery, coronary artery bypass grafting was also found to be closely related to the length of stay [44]. Lee et al. [42] reported that various factors such as demographic characteristics, medical institution and medical use characteristics, and disease characteristics all influenced the length of stay in patients with ischemic heart disease. In a study of patients with acute myocardial infarction, which is the majority of ischemic heart disease, it is reported that the location of the hospital and insurance coverage factors was the main factors in determining the length of stay [28]. As such, it is reported that there were some differences in the results of studies on factors related to the length of stay in ischemia, making it difficult to make consistent inferences [27]. There was a limit to generalizing detailed differences between diseases to large-scale epidemiological studies such as the Korea Medical Panel and the National Health and Nutrition Examination Survey, and to generalize the details and identify factors. In the future, an in-depth investigation into the mechanism of the occurrence of these differences should be continued.

It can be reported that regular physical activity was an important factor in maintaining health and reducing medical expenses [45]. In this study, annual personal medical expenses were the lowest in the minimally active group $(\$ 1,149)$, and the inactive $(\$ 1,647)$ and active group $(\$ 1,738)$ were high (Table 4). In a 2017 study by the Korea Medical Panel on obese elderly women, annual personal medical expenses increased in the order of minimally active group $(\$ 1,169)$, active group $(\$ 1,304)$, and inactive group $(\$ 1,805)$ [46]. Oh, using the 2009 data from the Korea Medical Panel, said that the personal medical cost of the inactive group was $\$ 772$ ( $W 849,965)$ and the walking group was $\$ 471$ ( $W 518,374)$, a 1.64 times difference [47]. The reason that the medical expenses of this study were higher than Oh's medical expenses, and that the medical expenses of the vigorously physically active group were higher than those of the minimally active group might due to the difference between the years of the study subjects in 2009 and 2018, and additional expenses for disease treatment, and insufficient number of cases of active group (Table 4). It was thought that this was due to the small number of subjects participating in high-intensity physical activity due to the nature of ischemic heart disease. Although personal medical expenses in this study are the sum of the amount the subject has spent at medical institutions, it will be necessary to compare the total medical expenses including the sum of expenditures from private insurance and health insurance in the future.

Motion sensors, heart rate monitors, and questionnaires are used to measure the amount of physical activity [48]. In this study, physical activity was measured using the simple IPAQ type used in large-scale epidemiological studies such as the National Health and Nutrition Examination Survey. However, since the IPAQ simple type was for the last 7 days, it was difficult to measure the daily energy consumption when the type of physical activity was different from usual [49]. 


\section{CONCLUSION}

Compared to the inactive group, the OR of the prevalence of ischemia in the minimally active group decreased to $0.75(p<.01)$ and 0.36 $(p<.001)$ in the active group. When gender, age, smoking and drinking frequency were used as covariates, compared to the inactive group, the OR of the minimally active group was similar at 1.05, but the OR of the active group was $0.61(p<.05)$, indicating a significant difference. HRQoL and usual activities of ischemia showed a significant difference according to the level of physical activity $(p<.01)$, and the inactive group showed the low on HRQoL and it meant negative results. There was no significant difference among the 3 active groups in the inpatient days and the emergency days both ischemia $(p>.05)$ and non-ischemia ( $p>$.05). The outpatient days of ischemia was the highest in the inactive group, and there was a significant difference among the 3 active groups $(p<.01)$. Annual personal medical expenses of ischemia showed a significant difference according to the level of physical activity $(p<.01)$. In the ischemia group, annual personal medical expenses showed the lowest in the minimally active group, and the inactive and active groups were similar. However, in the non-ischemic group, there was no significant difference in personal medical expenses among activity levels $(p>.05)$.

\section{CONFLICT OF INTEREST}

There is no relationship that may affect this thesis.

\section{AUTHOR CONTRIBUTIONS}

Conceptualization, Writing, Review \& Editing: BK Lee.

\section{ORCID}

Byung-Kun Lee https:/orcid.org/0000-0002-0098-4164

\section{REFERENCES}

1. WHO: Physical activity Key facts [Internet]. [cited 03 September 2018]. Available from: http://www.who.int/en/news-room/fact-sheets/ detail/physical-activity.

2. Kochanek KD, Xu J, Arias Elizabeth. Mortality in the united states, 2019. NCHS Data Brief No. 395 National Center for Health Statistics;
2020.

3. Chandalia M, Abate N. Hyperlipidemia. In: Johnson L, editor. encyclopedia of gastroenterology. Academic Press. 2004. p. 403-10.

4. Park J. Factors influencing the length of stay ischemic heart disease utilizing medical information. J Kor Aca Ind Co Soc. 2017;18(10):35462.

5. Mathers CD, Loncar D. Projections of global mortality and burden of disease from 2002 to 2030. PLoS Med. 2006;3(11):e442

6. Kochanek KD, Xu J, Murphy SL, Miniño AM, Kung H. Deaths: preliminary data for 2009. National vital statistics reports: from the centers for disease control and prevention, National Center for Health Statistics, National Vital Statistics System. 2011;59(4):1-51.

7. Eckel RH, Jakicic JM, Ard JD, de Jesus JM, Houston Miller N, Hubbard VS, et al. 2013 AHA/ACC guideline on lifestyle management to reduce cardiovascular risk: a report of the american college of cardiology/american heart association task force on practice guidelines. J Am Coll Cardiol. 2014;63(25 Part B):2960-84.

8. Shiroma EJ, Lee I. Physical activity and cardiovascular health: lessons learned from epidemiological studies across age, gender, and race/ethnicity. Circulation. 2010;122(7):743-52.

9. Sattelmair J, Pertman J, Ding EL, Kohl III HW, Haskell W, Lee I. Dose response between physical activity and risk of coronary heart disease: a meta-analysis. Circulation. 2011;124(7):789-95.

10. Bell EJ, Lutsey PL, Windham BG, Folsom AR. Physical activity and cardiovascular disease in african americans in ARIC. Med Sci Sports Exerc. 2013;45(5):901.

11. Autenrieth CS, Evenson KR, Yatsuya H, Shahar E, Baggett C, Rosamond WD. Association between physical activity and risk of stroke subtypes: the atherosclerosis risk in communities study. Neuroepide. 2013;40(2):109-16

12. Florido R, Zhao D, Ndumele CE, Lutsey PL, McEvoy JW, Windham BG, et al. Physical activity, parental history of premature coronary heart disease, and incident atherosclerotic cardiovascular disease in the atherosclerosis risk in communities (ARIC) study. J Am Heart Ass. 2016;5(9):e003505.

13. Lu Y, Ballew SH, Kwak L, Selvin E, Kalbaugh CA, Schrack JA, et al. Physical activity and subsequent risk of hospitalization with peripheral artery disease and critical limb ischemia in the ARIC study. J Am Heart Ass. 2019;8(21):e013534.

14. Lloyd-Jones DM, Hong Y, Labarthe D, Mozaffarian D, Appel LJ, Van Horn L, et al. Defining and setting national goals for cardiovascular 
health promotion and disease reduction: the american heart association's strategic impact goal through 2020 and beyond. Circulation. 2010:2;121(4):586-613.

15. Dutton GR, Lewis CE. The look AHEAD trial: implications for lifestyle intervention in type 2 diabetes mellitus. Prog Cardiovasc Dis. 2015;58(1):69-75.

16. Look AHEAD Research Group. Cardiovascular effects of intensive lifestyle intervention in type 2 diabetes. N Engl J Med. 2013;369(2): 145-54.

17. Lee Y, Nam H, Chuang L, Kim K, Yang H, Kwon I, et al. South korean time trade-off values for EQ-5D health states: modeling with observed values for 101 health states. Val Health. 2009;12(8):1187-93.

18. Kim JH, Jung IK. Relationship among physical activities, nutrient intake, and health-related factors in menopausal women: based on 6th (2014) korean national health and nutrition examination survey (KNHANES). J Kor Ass Phys Educ Sport Gir Wom. 2016;30(2):23752.

19. de Arruda FN, Oonk MH, Mourits MJ, de Graeff P, Jalving M, de Bock GH. Determinants of health-related quality of life in elderly ovarian cancer patients: the role of frailty and dependence. Gynecol Oncol. 2019;153(3):610-5.

20. Laaksonen DE, Lakka HM, Salonen JT, Niskanen LK, Rauramaa R, Lakka TA. Low levels of leisure-time physical activity and cardiorespiratory fitness predict development of the metabolic syndrome. Diabetes Care. 2002;25(9):1612-8.

21. Lee JA. Relationship between grip strength and prevalence of hypertension in korean adults: the sixth korea national health and nutrition examination survey (2015). J Kinesiol. 2017;19(3):53-60.

22. Sari N. Physical inactivity and its impact on healthcare utilization. Health Econ. 2009;18(8):885-901.

23. Kwak Kl, Baek CH, Ryu SY. Relationship between the physical activity levels and health care utilization in korean elderly. J Kor Acad Ind Co Soc. 2015;16(1):617-26.

24. Woolcott JC, Ashe MC, Miller WC, Shi P, Marra CA, PACC Research Team. Does physical activity reduce seniors' need for healthcare?: a study of 24281 Canadians. Br J Sports Med. 2010;44(12):902-4.

25. Wu J, Davis-Ajami ML, Lu ZK. Real-world impact of ongoing regular exercise in overweight and obese US adults with diabetes on health care utilization and expenses. Prim Care Diab. 2019;13(5):430-40.

26. Daghistani TA, Elshawi R, Sakr S, Ahmed AM, Al-Thwayee A, AlMallah MH. Predictors of in-hospital length of stay among cardiac pa- tients: a machine learning approach. Int J Cardiol. 2019;288:140-7.

27. Craig CL, Marshall AL, Sjostrom M, Bauman AE, Booth ML, Ainsworth BE, et al. International physical activity questionnaire: 12-country reliability and validity. Med Sci Sports Exerc. 2003;35(8):1381-95.

28. Nam HS, Kim KY, Kwon SS, Koh KW, Poul K. EQ-5D Korean valuation study using time trade off method. Seoul: Korea Centers for Disease Control and Prevention. 2007.

29. Verdaet D, Dendale P, De Bacquer D, Delanghe J, Block P, De Backer G. Association between leisure time physical activity and markers of chronic inflammation related to coronary heart disease. Atherosclerosis. 2004;176(2):303-10.

30. Palatini P, Puato M, Rattazzi M, Pauletto P. Effect of regular physical activity on carotid intima-media thickness. Results from a 6-year prospective study in the early stage of hypertension. Blood Press. 2011;20 (1):37-44.

31. Plotnikoff RC, Lippke S, Courneya K, Birkett N, Sigal R. Physical activity and diabetes: an application of the theory of planned behaviour to explain physical activity for type 1 and type 2 diabetes in an adult population sample. Psycho Health. 2010;25(1):7-23.

32. Plotnikoff RC, Lippke S, Trinh L, Courneya KS, Birkett N, Sigal RJ. Protection motivation theory and the prediction of physical activity among adults with type 1 or type 2 diabetes in a large population sample. Br J Health Psycho. 2010;15(3):643-61.

33. American College of Sports Medicine. ACSM's resource manual for guidelines for exercise testing and prescription. Wolters Kluwer: Lippincott Williams \& Wilkins; 2012.

34. Cornelissen VA, Smart NA. Exercise training for blood pressure: a systematic review and meta-analysis. J Am Heart Ass. 2013;2(1):e004473.

35. Moraes MR, Bacurau RF, Casarini DE, Jara ZP, Ronchi FA, Almeida SS, et al. Chronic conventional resistance exercise reduces blood pressure in stage 1 hypertensive men. J Strength Cond Res. 2012;26(4): $1122-9$.

36. Helmrich SP, Ragland DR, Leung RW, Paffenbarger Jr RS. Physical activity and reduced occurrence of non-insulin-dependent diabetes mellitus. N Engl J Med. 1991;325(3):147-52.

37. Look AHEAD Research Group, Wing RR. Long-term effects of a lifestyle intervention on weight and cardiovascular risk factors in individuals with type 2 diabetes mellitus: four-year results of the Look AHEAD trial. Arch Intern Med. 2010;27;170(17):1566-75.

38. Pietrzak RH, Tsai J, Kirwin PD, Southwick SM. Successful aging among older veterans in the united States. Am J Geria Psych. 2014;22 
(6):551-63.

39. Marengoni A, Angleman S, Melis R, Mangialasche F, Karp A, Garmen A, et al. Aging with multimorbidity: a systematic review of the literature. Age Res Revi. 2011;10(4):430-9.

40. Fraga MJ, Cader SA, Ferreira MA, Giani TS, Dantas EH. Aerobic resistance, functional autonomy and quality of life (QoL) of elderly women impacted by a recreation and walking program. Arch Gerontol Geriatr. 2011;52(1):e40-3.

41. Sevick MA, Dunn AL, Morrow MS, Marcus BH, Chen GJ, Blair SN. Cost-effectiveness of lifestyle and structured exercise interventions in sedentary adults: results of project ACTIVE. Am J Prev Med. 2000;19 (1):1-8.

42. Lee JB, Woo H. Determinants of length of stay in ischemic heart disease patients. J Health Inf Sta. 2020;45(1):52-9.

43. Park J. Factors influencing the length of stay ischemic heart disease utilizing medical information. J Kor Aca Ind Co Soc. 2017;18(10):35462.

44. Choi Y, Kim Y, Hong S. Development of severity-adjusted length of stay in ischemic heart disease. J Kor Data Anal Soc. 2015;17(1):407-21. 45. Martin MY, Powell MP, Peel C, Zhu S, Allman R. Leisure-time physical activity and health-care utilization in older adults. J Aging Phys Act. 2006;14(4):392-410.

46. Kwon MG, Lee HB, Lim KM, Lee HK, Kim TS. Differences in quality of Life, subjective health status, and medical expenses of obese elderly women according to their physical activities. Kor Soc Study Phys Edu. 2021;25(4):309-23.

47. Oh YH. An econometric analysis of the difference between exercisers and non-exercisers in medical care use. Health Soc Welf Rev. 2013;33 (4):471-96.

48. Colbert LH, Matthews CE, Havighurst TC, Kim K, Schoeller DA. Comparative validity of physical activity measures in older adults. Med Sci Sports Exerc. 2011;43(5):867-76.

49. Yang YJ, Yoon YS, Lee ES, Shin SH, Oh SW, Kim DH, et al. Development of self-administered questionnaire for the assessment of physical acitivity. Kor J Health Prom. 2005;5(3):178-98. 